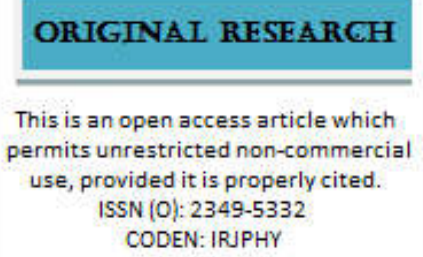

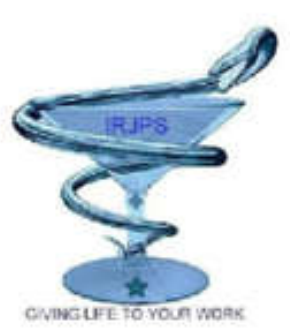

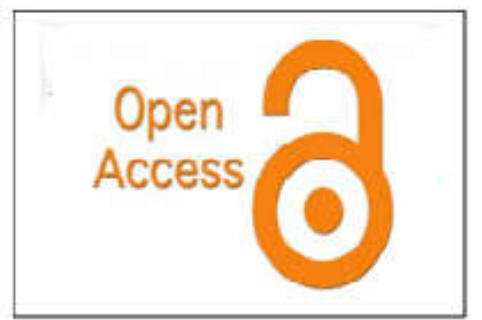

\title{
ANTIMICROBIAL POTENTIAL OF TRADITIONALLY USED ESSENTIAL OILS ON DIFFERENT PATHOGENIC MICROORGANISMS
}

\author{
Tamojit Lodh, Soumitra Sau, Sayan Nandi, Nurul Hasan Poilan, Haider Mollik, Bhakti. B. Barik, \\ Saumendu Deb Roy, Ramesh K. Dasgupta*
}

Department of Pharmacognosy, Bharat Technology, Banitabla, Uluberia, Howrah

\section{Submitted on: 16.11.18; $\quad$ Revised on: 23.11.18; $\quad$ Accepted on: 28.11.18}

\begin{abstract}
:
Eessential oils have been known for their biologic activities in the folkloric medicine in many countries from many centuries. The objective of our study was to investigate the antibacterial activity of essential oil of Allium sativum, Myristica fragrans, Piper nigrum, Citrus limon, Citrus sinensis, Coriandrum sativum and Eucalyptus globulus against different microorganisms. Anti-microbial activity was carried out against four strains of bacteria. Two stains of Gram-negative bacteria [Escherichia coli, Pseudomonas aeruginosa] and two strains of Gram-positive bacteria [Streptococcus pneumonia and Staphylococcus aureus].The study showed that essential oil from Allium sativum and Myristica fragrans have good antimicrobial activity against the tested strains. But essential oil from Citrus limon and Citrus sinensis, have very less activity as compare to Standard. Coriandrum sativum essential oil and Piper nigrum essential oil showed moderate activity.
\end{abstract}

KEY WORDS: Volatile oils, Antimicrobial, Disc diffusion.

Corresponding Author: Ramesh Kumari Dasgupta Indian Research Journal of Pharmacy and Science; 19(2018)1669-1673;

E-mail: minudasgupta007@gmail.com

Journal Home Page: https://www.irjps.in

Phone: +91-9073221120 DOI: 10.21276/irjps.2018.5.4.5 


\section{INTRODUCTION}

Microorganisms are the concealed enemies to the mankind. They are small but cause a very profound damage in human body as well as other living organism. The agents, which have the capacity to kill the microbes or arrest the multiplication, are called the antimicrobial agents or drugs. There are a lot of antimicrobial drugs of which some are discovered or established and some are hidden in the nature. Current research on natural molecules and products primarily focuses on plants. Since they can be sourced more easily and be selected based on their ethno- medicinal uses. A wide range of medicinal plants parts is used to extract as raw drugs and they possess varied medicinal properties. Plant used for traditional medicine contains a wide range of substances that can be used to treat chronic as well as infectious diseases.

Essential oils (Eos) are regarded as "natural" alternatives to chemical preservatives and their use in foods meets the demand of consumers for minimally processed products ${ }^{1}$.Essential oils (EOs) are volatile liquids that are extracted from plants. The main constituents of essential oils - terpenes, terpenoids, aromatic, aliphatic constituentsand some hydrocarbons including carbohydrates, phenols, alcohols, ethers, aldehydes and ketones are responsible for the biological activity of aromatic and medicinal plants as well as for their fragrance. They are mainly used for their organoleptic properties in many industrial domains.

In invitro analysis, many EOs have shown antiviral, antimycotic, antitoxigenic, antiparasitic and insecticidal properties $^{2}$.

Thus this study is aimed to investigate the antimicrobial activity of essential $\left(\mathrm{EO}_{\mathrm{s}}\right)$ from the variety of $\left(\mathrm{EO}_{\mathrm{s}}\right)$ producing plants such as Allium sativum, Myristica fragrans, Coriandrum sativum, Piper nigrum, Citrus limon, Citrus sinensis and Eucalyptus for preventing bacterial infection

\section{MATERIALS AND METHOD:}

\subsection{Collection of Plant Material:}

The buds of Allium sativum (FamilyAmaryllidaceae),nuts of Myristica fragrans (Family- Myristicaceae), Fruits, fruits of Piper nigrum (Family- Piperaceae), fruits of Citrus limon (sFamily-Rutaceae ), fruits of Citrus sinensis(Family-Rutaceae), leaves of Coriandrum sativum (Family-Apiaceae ) and leaves of Eucalyptus (Family-Myrtaceae) for preventing bacterial infection were purchased from the local market (Uluberia, Howrah). The essential oils were extracted by steam distillation using a Clevenger apparatus. $^{5-6}$

\subsection{Extraction of Volatile Oil:}

About $100 \mathrm{~g}$ of dried plant material accurately weighed and transferred to 1 litre distillation flask (Clevenger Apparatus) together with $250 \mathrm{ml}$ of water. Distillation tank was kept on the heating 
mantle and set the distillation assembly. Graduated receiver was filled with water avoiding any air bubbles. The out let near the upper end of the receiver was not tightened instead, loosely packed with cotton. Heating mantle was switched on and continued distillation for four hours at a rate which keeps the lower end of the condenser cool. The volatile oils thus isolated were being collected in the graduated receivers in which the aqueous portion of the distillate was automatically separated and returned to the distillation flask. Measured the volume of volatile oil (as separated out upper layer) in the graduated tube and calculated the percentage $\mathrm{v} / \mathrm{w}$ of isolated oil on a dry weight basis. The volume of isolated volatile oil from the given samples of Allium sativum was $0.8 \mathrm{ml}$, Myristica fragrans $0.9 \mathrm{ml}$, Coriandrum sativum $0.9 \mathrm{ml}$, Piper nigrum $0.8 \mathrm{ml}$, Citrus limon $1.2 \mathrm{ml}$, Citrus sinensiso $0.8 \mathrm{ml}$ and Eucalyptus $0.9 \mathrm{ml}$ respectively. Isolated essential oils were collected and stored in brown bottle at $-18^{\circ} \mathrm{C}$

\subsection{Antimicrobial Activity: ${ }^{4,5}$}

\subsubsection{Microorganisms}

The strains were obtained from Microbial Type Culture Collection, Jadavpur University, Kolkata, India. The stock culture was maintained on nutrient agar media at $37^{\circ} \mathrm{C}$. The $24 \mathrm{~h}$ culture of those microorganisms was used in the study. These organisms were preserved at $4^{\circ} \mathrm{C}$ and recultured once in a week. Standard strains of $S$. aureus, $P$. aeruginosa, E. coli, $S$ pneumonia were used for study.

\subsubsection{Screening for Antibacterial Activity by} Disk Diffusion method ${ }^{6}$

Nutrient Agar media was prepared and Sterilized in a flask and cooled to $45-50{ }^{\circ} \mathrm{C}$ and was distributed by pipette $(25 \mathrm{ml})$ in each pre sterilized petridishes, previously inoculated with $0.01 \mathrm{ml}$ of the nutrient broth cultures and swirled to distribute the medium homogenously. Disks injected with volatile oils $(500 \mu \mathrm{l} / \mathrm{ml})$ were placed on the solid agar medium by pressing slightly. The treated petri-plates were placed at $4^{\circ} \mathrm{C}$ for one hour and then incubated at $37^{\circ} \pm 0.1^{\circ} \mathrm{C}$ for $24 \mathrm{hrs}$. Same has been done for Standard drug Amoxicillin and control sample of DMSO. Lastly, the zones of Inhibitions formed on the media were measured with a transparent ruler in millimetres

\section{RESULTS AND DISCUSSION:}

The discovery of new properties of previously known natural products and used for other purposes should be encouraged. Especially when we are faced with the emerging microbial resistance to the currently employed antimicrobial agents. In our study we have evaluate the antibacterial activity of essential oil of as Allium sativum, Myristica fragrans, Coriandrum sativum, Piper nigrum, Citrus limon, Citrus sinensis and Eucalyptus for preventing bacterial infection against different

Ind Res J Pharm \& Sci|2018: Dec.: 5 (4) 1671 
microorganisms. Two stains of Gram-negative

bacteria [Escherichia coli, Pseudomonas

aeruginosa] and two strains of Gram-positive bacteria [Streptococcus pneumonia and Staphylococcus aureus] are used to carry out antimicrobial activity.

Table 1: Antimicrobial Potential of Traditionally used Essential Oils on different microorganisms

\begin{tabular}{|l|c|c|c|c|}
\hline \multirow{2}{*}{ Oils and Standard } & \multicolumn{3}{|c|}{ Zone of Inhibition (mm) } \\
\cline { 2 - 5 } & Escherichia coli & Pseudomonas & Streptococcus & Staphylococcus \\
& & aeruginosa & pneumonia & aureus \\
\hline Allium sativum Oil & 16 & 14 & 12 & 24 \\
\hline Myristica fragrans Oil & 15 & 25 & 12 & 12 \\
\hline Coriandrum sativum Oil & 10 & 11 & 14 & 16 \\
\hline Piper nigrum Oil & 12 & 16 & 12 & 8 \\
\hline Citrus limon Oil & 10 & 10 & 9 & 3 \\
\hline Citrus sinensis Oil & 8 & 7 & 5 & 23 \\
\hline Eucalyptus Oil & 6 & 7 & & \\
\hline Standard (Amox.) & 20 & 22 & & \\
\hline
\end{tabular}

\#\# Control Sample DMSO has not shown any activity dose was $500 \mu \mathrm{g} / \mathrm{ml}$

Among the oils tested in the present study, Allium sativum essential oil and Myristica fragrans essential oil showed good antimicrobial activity. Antimicrobial activity was similar to Amoxicillin for Allium sativum essential oil and Myristica fragrans with zone of inhibition ranging from 15 to 25mm. Citrus limon essential oil , Citrus sinensis essential oil Eucalyptus essential oil showed zone of inhibition ranging $3 \mathrm{~mm}$ to $16 \mathrm{~mm}$ which is less then the Standard. Coriandrum sativum essential oil and Piper nigrum essential oil showed moderate activity.

\section{ACKNOWLEDGEMENT:}

Authors are thankful to Prof. J. Mukherjee, Dept. of Pharmaceutical Technology, Jadavpur University, Jadavpur, Kolkata for proving the microbial strains. Authors would also take this opportunity to thank Principal and Director of Bharat Technology, Uluberia, Howrah for providing the facilities to carry out this work. 


\section{REFERENCES:}

1.Tassou, E.H. Drosinos and G.J.E. Nychasl Effects of essential oil from mint (Mentha piperita) on Salmonella enteritidis and Listeria monocytogenes in model food systems at $4 \mathrm{O}$ and $10^{\circ} \mathrm{C}$ C.C. Journal of Applied Bacteriology, 1995, 78, 593-600.

2. Burt , S. Essential oils: their antibacterial properties and potential applications in foods - a review International Journal of Food Microbiology $2004,94,223-253$

3. Deb Roy,S., Bania,R., Chakraborty,J., Goswami,R., Laila,R., Ahmed,S.A. Pharmacognostic, phytochemical, physicochemical property and antimicrobial activity studies of lemon peel oil. J. Nat. Prod. Plant Resour, 2012, 2,431435

4. Deb Roy,S., Apu, T., Dhrubajyoti,S., Arunav, K., Anupam, B., Bidyut,D. Antimicrobial Potential of Volatile Oil Isolated From Some Traditional Indian Spices. International Research Journal of Pharmacy ,2012, 3, 162-163.

5. Kumar, R. , Patia, S., Kumar, R., Ahmed, M.T., Khara , S., Laskar, M.F., Roy,S.D., Dasgupta, R.K., ANTIMICROBIAL POTENTIAL OF VOLATILE OIL ISOLATED FROM CARDAMOM. Indian Research Journal of Pharmacy and Science, |2017,4,1193-1200. 